\section{Exercise Transcutaneous Oximetry of the Buttocks, External Validation With Computed Tomography Angiography}

We read with great interest the paper from Audonnet et al about the accuracy of exercise transcutaneous oximetry $\left(\mathrm{Ex}-\mathrm{tcPO} \mathrm{P}_{2}\right)$ of the buttocks to detect stenosis greater than $75 \%$ in arteries towards the pelvic circulation. ${ }^{1}$ In our study in 2016 we used computed tomography angiography (CTA) as the gold standard. ${ }^{2}$ We tested the accuracy of Ex-tcPO to detect different levels of arterial stenosis of the lower limbs ( $\geq 50 \%, \geq 60 \%$, and $\geq 70 \%$ ) using a similar methodology. Of interest, we found quite similar results for the detection of stenosis $\geq 70 \%$. In our study, for stenosis $\geq 70 \%$, the sensitivity and specificity of proximal minimal DROP were $85.7 \%$ [67.7-94.8] and 75.0\% [59.6-85.9] respectively with an area under the curve (AUC) of 0.798 [0.683-0.885] whereas in Audonnet et al's study of stenosis $>75 \%$ the respective values for proximal minimal DROP were $80.5 \%$ and $72.3 \%$ with an AUC of 0.805 . Cut-offs were quite similar in both studies $\left(-16 \mathrm{mmHg}^{2}\right.$ and $\left.-15 \mathrm{mmHg}^{1}\right)$. In our opinion, these 2 studies strengthen interest in the use of Ex-tcPO $\mathrm{PO}_{2}$ to detect arterial stenosis towards the pelvic circulation. However, we would like to underscore that in our study we found a better AUC for the detection of stenosis $\geq 60 \%$. In that case, the AUC was 0.894 [0.7960.956 ] with $82.5 \%$ [67.6-91.5] sensitivity, $85.7 \%$ [67.7-94.8] specificity and $83.8 \%$ [75.1-92.6] accuracy. The cut-off value was also $-15 \mathrm{mmHg}$. Although our population was small, it seems that Ex-tcPO 2 with a cut-off $\leq-15 \mathrm{mmHg}$ better predicts stenosis $\geq 60 \%$ than stenosis $\geq 70 \%$ on CTA. Finally, we would like to add that this technique is also of interest for the assessment of distal claudication (in the calf), especially for patients who have incompressible arteries or a neuropathy where it is difficult to conclude that the pain has a vascular origin. ${ }^{2}$ We hope that based on interest in this technique and the published results, ${ }^{3,4} \mathrm{Ex}-\mathrm{tc} \mathrm{PO}_{2}$ will appear in future international guidelines as a second-line tool for peripheral artery disease diagnosis.

\section{References}

1. Audonnet M, Signolet I, Colas-Ribas C, Ammi M, Abraham P, Henni S. Exercise transcutaneous oximetry of the buttocks: External validation with computed tomography angiography. Circ J 2017; 81: 1123-1128.

2. Koch C, Chauve E, Chaudru S, Le Faucheur A, Jaquinandi V, Mahé G. Exercise transcutaneous oxygen pressure measurement has good sensitivity and specificity to detect lower extremity arterial stenosis assessed by computed tomography angiography. Medicine (Baltimore) 2016; 95: e4522.

3. Mahé G, Kaladji A, Le Faucheur A, Jaquinandi V. Internal iliac artery stenosis: Diagnosis and how to manage it in 2015. Front Cardiovasc Med 2015; 2: 33.

4. Mahé G, Kaladji A, Le Faucheur A, Jaquinandi V. Internal iliac artery disease management: Still absent in the update to TASC II (Inter-Society Consensus for the Management of Peripheral Arterial Disease). J Endovasc Ther 2016; 23: 233-234.

Loukman Omarjee, MD Olivier Stivalet, MD

Guillaume Mahe, MD, PhD Vincent Jaquinandi, MD, PhD Vascular Medicine Unit, INSERM CIC 1414, Rennes, France

Received April 28, 2017; accepted June 26, 2017; released online July 12, 2017

Mailing address: Vincent Jaquinandi, MD, PhD, Imagerie coeur-vaisseaux, Pole imagerie medicale et explorations fonctionnelles, CHU de Rennes - Universite de Rennes 1, Hopital Pontchaillou - 2, Rue Henri Le Guilloux, 35033 Rennes Cedex 9, France. E-mail: vincent.jaquinandi@chu-rennes.fr

ISSN-1346-9843 All rights are reserved to the Japanese Circulation Society. For permissions, please e-mail: cj@j-circ.or.jp 